University of Nebraska - Lincoln

DigitalCommons@University of Nebraska - Lincoln

\title{
Purification and characterization of acylation stimulating protein from porcine serum
}

\author{
Hong Zhang \\ University of Nebraska-Lincoln, hzhang2@unl.edu \\ Sheila K. Jacobi \\ University of Nebraska - Lincoln \\ Candace F. Toombs \\ University of Nebraska - Lincoln \\ Katherine H. Cianflone \\ McGill University \\ Natalya Nersesian \\ University of Nebraska-Lincoln, nnersesian2@unl.edu \\ See next page for additional authors
}

Follow this and additional works at: https://digitalcommons.unl.edu/biochemistrysarath

Part of the Biochemistry, Biophysics, and Structural Biology Commons

Zhang, Hong; Jacobi, Sheila K.; Toombs, Candace F.; Cianflone, Katherine H.; Nersesian, Natalya; Sarath, Gautam; and Miner, Jess L., "Purification and characterization of acylation stimulating protein from porcine serum" (2002). Gautam Sarath Publications. 16.

https://digitalcommons.unl.edu/biochemistrysarath/16

This Article is brought to you for free and open access by the Biochemistry, Department of at DigitalCommons@University of Nebraska - Lincoln. It has been accepted for inclusion in Gautam Sarath Publications by an authorized administrator of DigitalCommons@University of Nebraska - Lincoln. 


\section{Authors}

Hong Zhang, Sheila K. Jacobi, Candace F. Toombs, Katherine H. Cianflone, Natalya Nersesian, Gautam Sarath, and Jess L. Miner 


\title{
Purification and characterization of acylation stimulating protein from porcine serum
}

\author{
Hong Zhang ${ }^{a}$, Sheila K. Jacobi ${ }^{a}$, Candice F. Toombs ${ }^{a}$, Katherine H. Cianflone ${ }^{b}$, \\ Natalya Nersesiana, Gautam Sarath ${ }^{\mathrm{a}}$, and Jess L. Miner ${ }^{\mathrm{a}}$ \\ a Departments of Animal Science and Biochemistry, Biotechnology Center, \\ University of Nebraska-Lincoln, Lincoln, NE 68583-0908, USA \\ ${ }^{\mathrm{b}}$ McGill Unit for the Prevention of Cardiovascular Disease, \\ McGill University, Royal Victoria Hospital, Montreal, Quebec, Canada \\ Corresponding author - J. L. Miner, fax: 402-472-6362; email: jminer1@unl.edu
}

\begin{abstract}
A method for purifying acylation stimulating protein (ASP) from porcine serum is described. The mRNA encoding ASP was cloned by reverse transcriptase-polymerase chain reaction which predicted a 76 residue peptide. Based on this sequence, we generated antisera to a C-terminal peptide ( $\left.\mathrm{ASP}_{1-20}\right)$ which aided ASP purification. Identity of the purified protein was verified by N-terminal sequencing. The molecular mass of porcine ASP is 8926. Porcine ASP stimulated esterification of fatty acid into triacylglycerol in cultured human cells with potency similar to that of human ASP (twofold at $5 \mu \mathrm{M}$ ). Based on this evidence that ASP exists in porcine blood, and that it has acylation stimulating activity, we propose that ASP may play a role in regulation of energy storage in adipose tissue in the pig.
\end{abstract}

Keywords: Pig, Complement factor C3a, Acylation stimulating protein, Adipose tissue

Abbreviations: ASP, acylation stimulating protein; BCIP, 5-bromo-4-chloro-3-indolyl phosphate; BSA, bovine serum albumin; NBT, nitroblue tetrazolium; PBS, phosphate-buffered saline solution; PCR, polymerase chain reaction; RT, reverse transcriptase; TFA, trifluoroacetic acid.

Acylation stimulating protein (ASP) is believed to regulate lipid metabolism in adipocytes. In the search for causes of hyperapobetalipoproteinemia, Cianflone et al. [1] observed that adipocytes from afflicted patients were insensitive to a serum lipogenic factor. This factor, which they named ASP, can stimulate triacylglycerol synthesis in normal human adipocytes. Following purification, these researchers determined that ASP is identical to the complement $\mathrm{C} 3$ fragment, $\mathrm{C} 3 \mathrm{a}$, minus its $\mathrm{C}$ terminal arginine [2]. Purified human ASP (C3a-desArg) promotes fatty acid esterification, glucose uptake, and diacylglycerol acyltransferase activity in cultured human fibroblasts and adipocytes [3].

The pig's regulation of triacylglycerol synthesis is of considerable interest both as a model for the human and because excessive fat deposition can both increase production cost and reduce carcass value of agricultural swine. Therefore, we set out to develop methods for the study of ASP in the pig. We now report a method for purification of ASP from porcine serum.

\section{Materials and methods}

\section{Cloning of porcine ASP}

Total RNA was extracted from subcutaneous adipose tissue obtained at slaughter from male castrate pigs (Yorkshire/Landrace/Duroc crossbred, body weight $\sim 110 \mathrm{~kg}$ ). A restricted set of porcine cDNA was synthesized from total RNA by reverse transcriptase (RT; Superscript II; Gibco BRL, Gaithersburg, MD) derived from two animals using a reverse primer, 5'ACAGGAAGCTTGACAWGCTSACHGCCA-3' which flanks the $3^{\prime}$ end of human ASP in the complement 
C3 gene. Three RT reactions were executed. Two reactions were independent but used RNA from a common pig. The third reaction used RNA from a second pig. A 228-bp ASP coding region was amplified from each set of cDNA by polymerase chain reaction (PCR) using the reverse primer above and a forward primer, 5'-GGYGTGTTYGTGCTGAAYAAGAA-3', which also flanks ASP in the human complement $\mathrm{C} 3$ gene [2 and 4]. The PCR products were cloned into pBluescript 2KS+ (Invitrogen, Carlsbad, CA) and sequenced using $\mathrm{T} 7$ and T3 primers at the University of Nebraska DNA Sequencing Core Facility with a Li-COR sequencer and dye primer chemistry (LI-COR, Lincoln, NE). The PCR conditions were: (1) denaturation $3 \mathrm{~min}$ at $94^{\circ} \mathrm{C}$; (2) one cycle of $15 \mathrm{~s}$ at $94{ }^{\circ} \mathrm{C}, 2 \mathrm{~min}$ at $55^{\circ} \mathrm{C}$, and $2 \mathrm{~min}$ at $72{ }^{\circ} \mathrm{C}$; (3) 37 cycles of $15 \mathrm{~s}$ at $94{ }^{\circ} \mathrm{C}, 30 \mathrm{~s}$ at $55^{\circ} \mathrm{C}$, and $30 \mathrm{~s}$ at $72{ }^{\circ} \mathrm{C}$; and (4) 7 min extension at $72{ }^{\circ} \mathrm{C}$. All PCRs contained $1 \%$ DMSO.

\section{ASP Western blot assay}

We synthesized a peptide corresponding to the C-terminus of porcine ASP (CEYIAKLRQQHSRNKPLGLA) using FMOC-protected amino acids on a Pioneer Peptide Synthesizer (ABI). The synthetic peptide was purified and conjugated to BSA essentially as described earlier [5] and used to immunize a rabbit. Antisera obtained after the fourth boost was used to probe Western blots. Protein samples from 15\% SDS-PAGE were transferred to nitrocellulose membranes by a semi-dry electric transfer apparatus (Semiphor, Kirkegaard and Perry Laboratories, Gaithersburg, MD). Membranes were incubated with primary antibody raised against porcine serum ASP polypeptide (1:500) or a primary antibody raised against human plasma ASP (1:1000; 6). Detection was by anti-rabbit IgG conjugated to alkaline phosphatase. The substrates were nitroblue tetrazolium (NBT) and 5-bromo-4-chloro-3-indolyl phosphate (BCIP).

\section{Purification of ASP}

Fresh blood was obtained from Yorkshire/Landrace/ Duroc crossbred pigs at slaughter (body weight approximately $110 \mathrm{~kg}$ ), allowed to clot $4 \mathrm{~h}$ at $4{ }^{\circ} \mathrm{C}$, and centrifuged $20 \mathrm{~min}$ at $4000 \mathrm{~g}$. Following the protocol for purification of human ASP [7], serum was spiked with inulin $\left(0.5 \% \mathrm{w} / \mathrm{v}\right.$ final concentration) and $\mathrm{MgCl}_{2}$ (2 mM final concentration) and stirred $1 \mathrm{~h}$ at $37^{\circ} \mathrm{C}$ to enhance activation of complement. Globular proteins were precipitated with concentrated $\mathrm{HCl}$ (1 M final concentration) and separated by centrifugation for $30 \mathrm{~min}$ at $4000 \mathrm{~g}$. The supernatant was neutralized to $\mathrm{pH} 7.4$ by addition of $10 \mathrm{~N} \mathrm{NaOH}$, stored at $-20^{\circ} \mathrm{C}$, and used for chromatographic purification of ASP.

The supernatant from the acid precipitation step was thawed on ice and applied to a C18 Sep-pak column
(37-55 $\mu \mathrm{m}, 1.5 \times 10 \mathrm{~cm}$; Waters) previously wetted with 3 volumes methanol and equilibrated with 10 volumes of $0.1 \%$ trifluoroacetic acid (TFA). Unbound proteins were removed by washing with 10 volumes of $20 \%$ acetonitrile (ACN) $-0.1 \%$ TFA. Bound proteins were eluted with 6 volumes of $80 \%$ ACN- $0.1 \%$ TFA. One column volume fractions were collected. Fractions rich in ASP based on 15\% SDS-PAGE and immunoblotting analysis (generally fractions one to two) were pooled, lyophilized, and redissolved in buffer A (10 mM Tris, $10 \mathrm{mM} \mathrm{NaCl}, \mathrm{pH}$ 7.1) plus $0.1 \%$ TFA. The dissolved sample was further fractionated by cation exchange (Poros PE-Biosystems, $\mathrm{HS} / \mathrm{M}, 4.6 / 100 \mathrm{~mm}$ ) pre-equilibrated with 10 volumes buffer A using an ABI BioCAD Workstation. After washing with five column volumes of buffer $\mathrm{A}$, bound proteins were eluted with a linear $0-1.5 \mathrm{M}$ gradient of $\mathrm{NaCl}$ in buffer $\mathrm{A}$ at a flow rate of $4 \mathrm{ml} / \mathrm{min}$ over 15 column volumes. The elution peak (corresponding to $1 \mathrm{M} \mathrm{NaCl}$ ) was pooled and directly loaded into a reversed-phase column (Poros PE-Biosystems, R1/H, 4.6×100 mm) preequilibrated with $15 \%$ ACN-0.1\% TFA using an ABI BioCAD workstation. After washing with three column volumes of $15 \%$ ACN-0.1\% TFA, bound proteins were eluted with a linear gradient from $15 \%$ ACN-0.1\% TFA to $85 \%$ ACN-0.1\% TFA at a flow rate of $3 \mathrm{ml} / \mathrm{min}$ over 15 column volumes. Peaks were pooled from several runs and lyophilized. Purified porcine ASP was reconstituted and dialyzed into $10 \mathrm{mM}$ sodium phosphate buffer $(\mathrm{pH} 7.1)$ and stored frozen $\left(-80^{\circ} \mathrm{C}\right)$. Protein concentrations were determined with the BCA Protein Assay Kit (Pierce, Rockford, IL) using bovine albumin as a standard.

\section{Mass spectroscopy}

Electrospray mass spectroscopy was performed on purified ASP obtained after reverse-phase chromatography at the University of Nebraska mass spectroscopy core facility using a Finnigan LCQ ion trap mass spectrometer.

\section{Amino acid sequencing}

Approximately $3 \mu \mathrm{g}$ purified ASP protein was fractionated by $15 \%$ SDS-PAGE and electroblotted to a polyvinylidene difluoride membrane. The membrane was stained with amido black [8] and bands corresponding to ASP were excised and sequenced on an ABI-Procise 494 sequencer using manufacturer-suggested protocols for 20 cycles.

\section{Acylation stimulating activity assay}

Human skin fibroblasts were plated in Dulbecco's modified Eagle's medium/F12 containing $100 \mu \mathrm{M}[9,10-$ $\left.{ }^{3} \mathrm{H}(\mathrm{N})\right]$ oleic acid:BSA (5:1) and grown to $90 \%$ confluence according to Baldo et al. [7]. Cultures were treated for $6 \mathrm{~h}$ with PBS $(n=9) ; 5 \mu \mathrm{M}$ human ASP $(n=9)$; or $5 \mu \mathrm{M}$ 
porcine ASP $(n=3)$. An organic extract of each culture was subjected to thin layer chromatography and triacylglycerol fractions were analyzed in a $\beta$-counter to quantify oleate esterification.

\section{Results and discussion}

\section{cDNA sequence}

The RT-PCR 580-bp product was completely homologous to porcine complement C3 (Accession No. 110278). This sequence exactly matches a subsequent full-length clone (Accession No. 154933). The region encoding ASP is aligned with human ASP in Figure 1. This region possibly has two polymorphisms which do not impact amino acid sequence. Base 187 was $C$ versus $T$ and base 207 was $C$ versus $A$ in one of the two independent clones sequenced. Porcine ASP nucleic acid sequence is $79.4 \%$ homologous to human ([4]; K02765), 72.4\% homologous to mouse ( [9]; K02782), 74.6\% homologous to rat ( [9]; X52477), and 86.0\% homologous to bovine (Accession No. AF110279). The porcine cDNA predicts a 76amino acid ASP sequence which is 75.0, 78.9, 76.3, and $84.4 \%$ similar to human, mouse, rat, and bovine ASP amino acid sequences, respectively.

\section{ASP purification}

Porcine ASP was obtained from serum in four steps. First, complement was activated with inulin and extraneous proteins were acid precipitated. The remaining supernatant was subjected sequentially to C18 chromatography and cation exchange chromatography. A

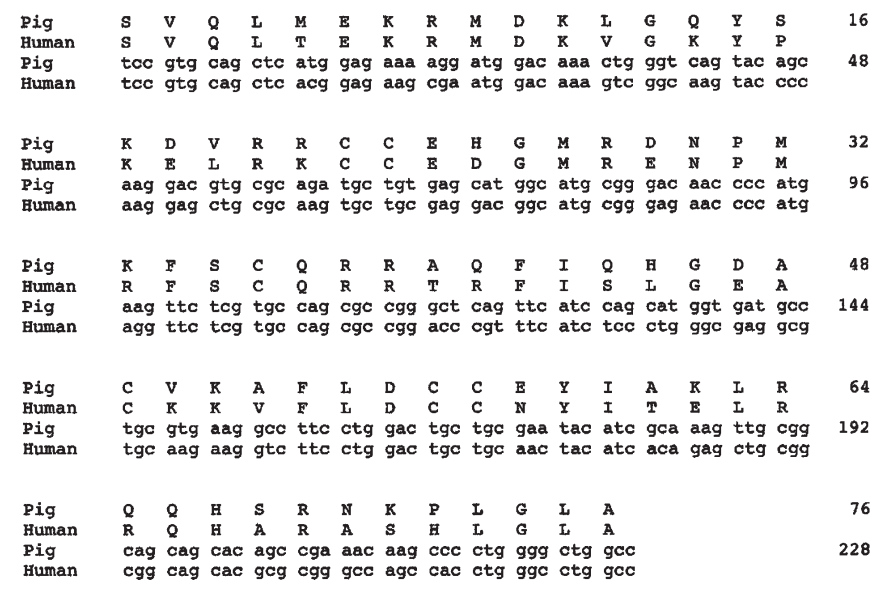

Figure 1. Region of porcine complement C3 cDNA which encodes ASP, predicted ASP protein sequence, and alignment with human complement C3 [4]. Analysis of two independent clones revealed a possible polymorphism at positions 187 (C versus T) and 207 (C versus A) which does not affect predicted amino acid sequence. The above sequence exactly matches that reported by Wimmers et al. [12]. major peak was eluted by $1 \mathrm{M} \mathrm{NaCl}$ in the cation exchange column and collected as ASP-rich fractions (Figure $2 \mathrm{~A}_{1}$ ) based on SDS-PAGE (Figure 2 $\mathrm{A}_{2}$ ) and Western blot analyses ( Figure $2 \mathrm{~A}_{3}$ ). Following a second reversephase step in which ASP eluted at approximately $43 \%$ $\mathrm{ACN}$ as a single, dominant peak ( Figure 2B), the resulting porcine ASP was near homogeneity ( Figure 3, lane 5). The yield from $400 \mathrm{ml}$ porcine serum was $5.5 \mathrm{mg}$ ASP. The relative purification and cumulative ASP yield at each step are presented in Table 1 and Figure 3.

\section{ASP characterization}

The molecular mass of purified porcine ASP determined by mass spectrometry is 8926 which corresponds to the calculated mass of the predicted amino acid sequence. Porcine ASP migrates slightly faster in 15\% SDS-PAGE (estimated $8.9 \mathrm{kDa}$; Figure 4A, lane 1, 2) than human ASP, perhaps because human ASP is slightly larger (MW=8932). N-terminal sequencing of 20 residues of porcine ASP revealed an exact match to the predicted sequence (Figure 1).

Our antisera raised against porcine ASP polypeptide do not crossreact with human ASP (Figure 4B, lane 2), although it can clearly detect porcine ASP on Western blots ( Figure 4B, lane 1). Similarly, the antibody raised against purified human ASP [6] does not react strongly with porcine ASP on Western blots ( Figure 4C, lane 1). Assay of ASP in porcine serum can be made, however, if the serum is acid precipitated. We observed that the concentration of ASP was elevated in pigs following a high fat meal versus following an overnight fast (not shown). This compares favorably to the response of ASP to fat consumption in humans [10].

Porcine ASP stimulated esterification of oleate into triacylglycerol in human fibroblasts. Mean $( \pm$ SD) esterification was $108( \pm 8.5), 218( \pm 16.6)$, and $217 \pm 41.9$ pmol triacylglycerol/mg cell protein for control, $5 \mu \mathrm{M}$ human ASP, and $5 \mu \mathrm{M}$ porcine ASP treatments, respectively. We have not investigated the mechanism by which porcine ASP enhances fatty acid esterification. Presumably it functions in the same manner as human ASP. Human ASP stimulates diacylglycerol acyltransferase, apparently via protein kinase $C$ signalling from a cell surface receptor [13]. The effect of ASP on incorporation of fatty acid into triacylglycerol can be attributed to esterification. Van Harmelen et al. [14] have reported that, like insulin, ASP increases esterification, but unlike insulin, ASP does not influence lipolysis. Given the significant concurrent cycling of esterification and lipolysis, a small increase in esterification will impart a large increase in net triacylglycerol accumulation, assuming a constant rate of lipolysis. Consequently, the twofold enhancement of esterification caused by porcine ASP is evidence that this molecule may be a powerful determinant of adipose tissue lipid metabolism. Interestingly, we observed only a modest effect of porcine ASP on lipid syn- 

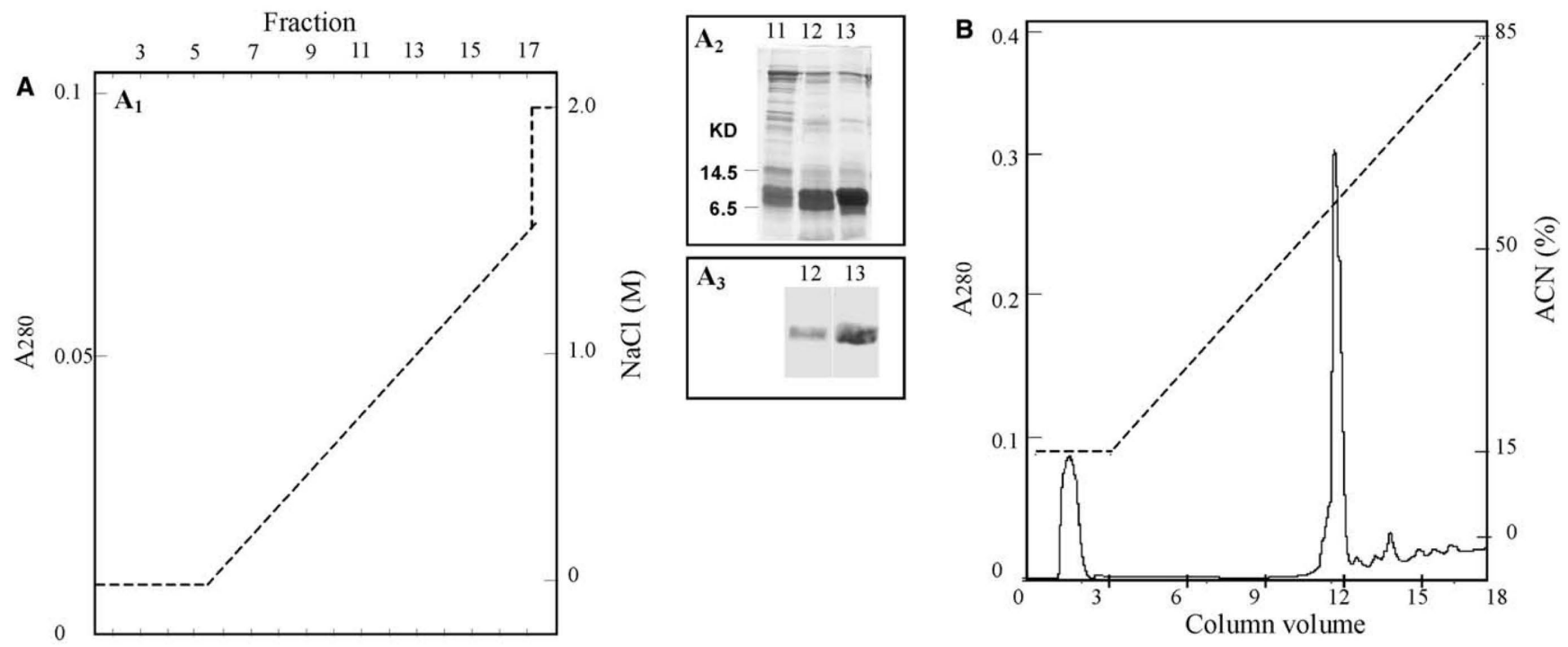

Figure 2. Purification of ASP from porcine serum. $\left(\mathrm{A}_{1}\right)$ After primary reverse-phase C18 chromatography, ASP-containing fractions were eluted from a HS/M cation exchange column with a linear 0-1.5 M gradient of $\mathrm{NaCl}$ (dashed line) and pooled based on SDS-PAGE and Western analyses. Porcine ASP eluted at $1 \mathrm{M} \mathrm{NaCl}$. $\left(\mathrm{A}_{2}\right)$ The Coomassie brilliant blue-stained 15\% SDS-PAGE of selected fractions referenced to fraction numbers from panel $A_{1}$. Each sample was concentrated, desalted, and dissolved in Laemmli's buffer before electrophoresis. $\mathrm{A}_{3}$ Western blot of samples identical to those in panel $\mathrm{A}_{2}$ probed with anti-porcine ASP polypeptide antibody. (B) R1H reverse-phase chromatography of ASP-containing fractions from HS/M column. Proteins were eluted with a linear 15-85\% ACN gradient (dashed line). A sharp, single peak rich in ASP was pooled and lyophilized.

thesis in porcine adipose tissue explant cultures [15]. However, this difference in response as compared to the cell cultures reported here may be due to technical problems of making such measurements in tissue pieces versus monolayers of cells. On the other hand, it remains to be demonstrated that porcine adipocytes are responsive to porcine ASP.

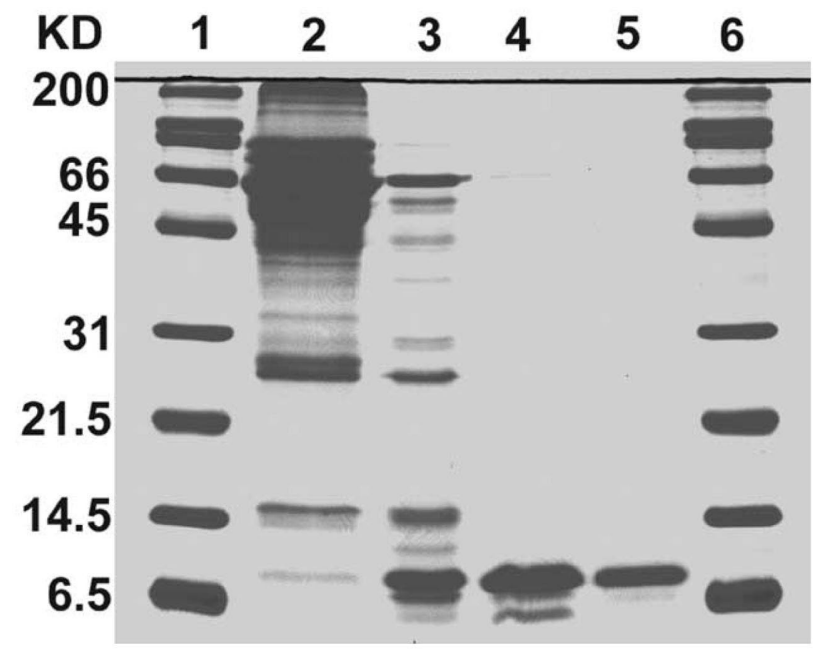

Figure 3. SDS-PAGE (15\%) analysis of chromatographic steps in the purification of ASP from porcine serum. Lanes 1 and 6: Bio-Rad broad range marker. Lane 2: Clarified supernatant after acid precipitation and neutralization. Lane 3: Fractions pooled from C18 reverse phase. Lane 4: Fractions pooled from HS/M cation exchange. Lane 5: Fractions pooled from R1H reverse phase.
We conclude that ASP can be obtained from pig blood and that porcine ASP exhibits activity comparable to ASP derived from human blood. Like human ASP, it is resistant to treatment with strong acid and hydrophobic treatments. This information should be of value to those studying regulation of adiposity in swine, given the dearth of hormones known to promote triacylglycerol synthesis in porcine adipose tissue. We propose that the complement proteins, ASP and adipsin [16], may play a role in regulation of adipose tissue function in the pig.

Table 1. ASP purification from porcine serum

\begin{tabular}{lcc}
\hline Purification step & Protein $^{\mathrm{a}}(\mathrm{mg})$ & $\mathrm{ASP}^{\mathrm{b}}(\mathrm{mg})$ \\
\hline Serum $(400 \mathrm{ml})$ & 28,000 & $\mathrm{ND}^{\mathrm{c}}$ \\
Neutralized acid & 3100 & 28 \\
$\quad$ supernatant $(246 \mathrm{ml})$ & & \\
C18 & 30.6 & 8.0 \\
HS/M & 10.2 & 6.9 \\
R1H & 5.5 & 5.5 \\
\hline
\end{tabular}

a Total protein concentration was determined by the BCA procedure except that protein content of serum was assumed [11].

b ASP protein was quantified by scanning Coomassie bluestained SDS-PAGE gels using a Hitachi Genetic Systems Instrument (Gene-Snap 2.60.0.14; Synoptics; Cambridge, England). For the above calculations, the R1H-eluted ASP was considered pure and thus used as standard for quantifying ASP in the other samples (CCDBIO Gene-Tools Version 2.12.05; Hitachi Genetic Systems; Alameda, CA).

${ }^{\mathrm{c}}$ Not determined. 


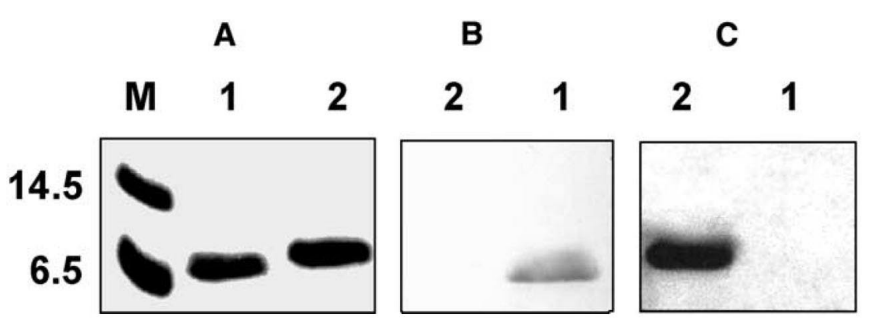

Figure 4. SDS-PAGE and Western analyses of purified porcine and human ASP. (A) SDS-PAGE analysis. Lane 1: Porcine ASP $(2 \mu \mathrm{g})$; Lane 2: Human ASP $(2 \mu \mathrm{g})$; Lane M: Molecular weight markers (kDa). (B) Western blot of the same samples as in panel A probed with anti-porcine ASP polypeptide antibody. (C) Western blot of the same samples as in panel A probed with anti-human ASP antibody.

\section{Acknowledgments}

The paper is supported by grants from the National Pork Producers Council on behalf of the Nebraska Pork Producers Association, the Layman Fund, the Agricultural Research Division, the Research Council, and by the Center for Biotechnology, University of Nebraska-Lincoln, funded through the Nebraska Research Initiative. The manuscript has been assigned Journal Series No. 13412, Agricultural Research Division, University of Nebraska.

\section{References}

1. K. M. Cianflone, M. H. Maslowska, and A. D. Sniderman. Impaired response of fibroblasts from patients with hyperapobetalipoproteinemia to acylation-stimulating protein. J. Clin. Invest. 85 (1990), pp. 722-730.

2. A. Baldo, A. D. Sniderman, S. St. Luce, R. K. Avramoglu, M. Maslowska, B. Hoang, J. C. Monge. A. Bell, S. Mulay, and K. Cianflone, The adipsin-acylation stimulating protein system and regulation of intracellular triglyceride synthesis. J. Clin. Invest. 92 (1993), pp. 1543-1547.

3. A. D. Sniderman and K. Cianflone. The adipsin-ASP pathway and regulation of adipocyte function. Ann. Med. 26 (1994), pp. 389-393.

4. M. H. De Bruijn and G. H. Fey. Human complement component C3: cDNA coding sequence and derived primary structure. Proc. Natl. Acad. Sci. USA 82 (1985), pp. 708-712.

5. C. J. Chastain, M. Botschner, G. E. Harrington, B. J. Thompson, S. E. Mills, G. Sarath, and R. Chollet. Further analysis of maize C-4-pyruvate, orthophosphate dikinase regulatory phosphorylation by its bifunctional regulatory protein using selective substitution of the regulatory Thr/456 and catalytic His/458 residues. Arch. Biochem. Biophys. 375 (1999), pp. 165-170.

6. J. Saleh, L. K. M. Summers, K. Cianflone, B. A. Felding, A. D. Sniderman, and K. N. Frayn. Coordinated release of acylation stimulating protein (ASP) and triacylglycerol clearance by human adipose tissue in vivo in the postprandial period. J. Lipid Res. 39 (1998), pp. 884-891.

7. A. Baldo, A. D. Sniderman, S. St. Luce, X. Zhang, and K. Cianflone. Signal transduction pathway of acylation stimulating protein: involvement of protein kinase C. J. Lipid Res. 36 (1995), pp. 1415-1426.

8. A. R. Penheiter, S. M. G. Duff, and G. Sarath. Soybean root nodule acid phosphatase. Plant Physiol. 114 (1997), pp. 597-604.

9. H. Domdey, K. Wiebauer, M. Kazmaier, V. Muller, K. Odink and G. Fey. Characterization of the mRNA and cloned cDNA specify the third component of mouse complement. Proc. Natl. Acad. Sci. USA 79 (1982), pp. 7619-7623.

10. K. Cianflone, H. Vu, M. Walsh, A. Baldo and A. Sniderman. Metabolic response of acylation stimulating protein to an oral fat load. J. Lipid Res. 30 (1989), pp. 1727-1733.

11. A. C. Guyton. Textbook of Medical Physiology. W. B. Saunders, Philadelphia, PA (1986).

12. K. Wimmers, S. Ponsuksili, S. Mekchay, T. Hardge, F. Schmoll, and K. Schellander. The complement system and its component C3: candidates for natural resistance to micro-organisms. Archiv fur Tierzucht-Archives Anim. Breeding 42 (1999), pp. 116-118.

13. K. Cianflone. The acylation stimulating protein pathway: clinical implications. Clin. Biochem. 30 (1997), pp. 301-312.

14. V. Van Harmelen, S. Reynisdottir, K. Cianflone, E. Degerman, J. Hoffstedt, K. Nilsell, A. Sniderman, and P. Arner. Mechanisms involved in the regulation of free fatty acid release from isolated human fat cells by acylation-stimulating protein and insulin. J. Biol. Chem. 274 (1999), pp. 18243-18251.

15. S. K. Jacobi and J. L. Miner. Human acylation-stimulating protein and lipid biosynthesis in bovine adipose tissue explants. J. Anim. Sci. 80 (2002), pp. 751-756.

16. J. L. Miner, K. J. Hahn, M. E. Spurlock and N. R. Staten. Characterization of porcine adipsin. Protein Expr. Purif. 23 (2001), pp. 14-21. 